\title{
REPAIR, REHABILITATION \&RETROFITTING OF RCC For Sustainable DeVElopMENT With CASE STUDIES
}

\author{
J. Bhattacharjee \\ Prof.\& Advisor, Department of Civil Engineering, Amity University, Noida, UP, India; \\ former Chief Engineer \& Jt. Director General, (MES/MOD)
}

\begin{abstract}
The construction material mainly reinforced concrete is being used extensively for various types of construction projects. However, the deterioration of Reinforced Concrete structures is recognized as a major problem worldwide. Apart from requiring regular maintenance, many structures require extensive Repair, Rehabilitation \&Retrofitting. Over a period of time, as these structures become older, we find in them certain degradation or deterioration with resultant distress manifested in the form of cracking, splitting, delaminating, corrosion etc. Such deteriorated structures can be rehabilitated and retrofitted by using various types of admixtures \& modern repair materials. The paper brings out the present state of concrete structures \& the major areas where improvement is needed during its service life stage for sustainable development \& also the method of carrying out Repair, Rehabilitation \&Retrofitting.This has been brought in details in the paper along with Case studies, where the Author of the paper was directly involved in planning and execution of the jobs.
\end{abstract}

\section{KEYWORDS}

Rehabilitation, Retrofitting, Sustainable Development, Polymers, Admixtures

\section{INTRODUCTION}

Sustainable development has become the challenge for humanity particularly with rapid growth of urbanization. Critical issue is to provide food, shelter and other basic needs to rapidly growing world population and save natural resources on which the very existence of population depends. We have got wide variation in the Perception of responsibility to future generations and ethical issue. There is an urgent need of us the professional to understand and implement cleaner production and sustainable development and maintenance objectives at all level of responsibility.

The buildings in which we live, work, and play protect us from Nature's extremes. Yet they also affect our health and environment in countless ways. The design, construction, operation, maintenance, and removal of buildings takes enormous amounts of energy, water and materials, and generates large quantities of waste, air and water pollution. As the environmental impact of buildings becomes more apparent, a concept called green building is gaining momentum. Green or sustainable building is the practice of creating healthier and more resource efficient models of construction, renovation, operation, maintenance, and demolition. Research and experience increasingly demonstrates that when buildings are designed and operated with their lifecycle impacts in mind, they can provide great environmental, economic, and social benefits. It is worth noticing that most of us talk about energy consumption and pollution because of industry and transport, when about $40 \%$ of the total energy produced is consumed by buildings only. Hence sustainability in construction and maintenance has become so important, while developing all civil Engineering Infrastructures. 
There is a growing National/International concern about the premature deterioration of our buildings/structures, particularly concrete structures. Cement concrete is one of the most widely used construction material and has proved to be almost indispensable to the present day civilization. Though concrete is quite strong mechanically, it is highly susceptible to deterioration and thus gets damaged \& even fail ultimately, unless some measures are adopted to counter deterioration. Such measures would enhance the durability of structures. The maintenance of building is a lifelong continuous process. It has been observed that the minimum maintenance of concrete structures require an integral approach which need the introduction of as much preventive measures as possible in accordance with the basic established concept -"Prevention is always better than cure". Repair/rehabilitation/retrofitting is the fastest growing segment of the concrete industry. Across the globe, billions of dollars are spent annually in repair and restoration of distressed concrete structures. Thus selection and evaluation of repair materials and protective coatings is receiving more and more attention among Civil Engineers in the recent past. The new technologies and new repair materials, which have been extensively being used by the advanced countries, are also being tried in developed country like India. This paper highlights the present state of maintenance especially in developing country like India and about the utilization of those new techniques/materials for repair/restoration of the buildings/structures, for long term sustainable development [1].

\section{Present State Of Maintenance, Repair\& Rehabilitation}

It is a matter of serious concern of us the civil Engineers, that in some countries, the repair activities of structure done today account for nearly half the total annual expenditure on total construction activities [2]. Such a state of affairs is of great concern mainly for two reasons. Firstly, concrete is, in essence a proven, durable $\&$ mostly maintenance free material. This is exemplified by a large number of structures constructed properly more than half a century back \& is still in good stead today. Secondly, the know-how of making concrete, which does not need major repair/rehabilitation, is already well documented and is known to us. Inspite of all these, the trend of early deterioration of concrete structure continues unabated.

At present there is neither any established existing procedure, mandatory or otherwise, for periodical inspection of buildings/ structures and recording the structural defects and symptoms, like cracks, spalling ,corrosion, and deflection of structure, in a logical manner nor any record of structural repairs/rehabilitations carried out, is maintained properly even for public buildings. We have barged into a repair activity without adequate preparation. Persons involved in repair/rehabilitation need to be better civil engineers. In fact repair/rehabilitation/retrofitting activity is a much more advanced application of science and technology involved in civil engineering, which is the most difficult challenge to engineers. We need to opt for new techniques and materials to resolve these difficulties. We have enough options to select from various construction chemicals, minerals, methods for repairs/rehabilitations, the economics etc. to set right the damage. These all are to be considered in totality before deciding upon the repair/rehabilitation/retrofitting strategy $[9,10]$ and hence required enough background preparation.

Replacement of damaged materials is the trend for repair/rehabilitation. Mass scale replacements are convenient repair strategies, which were being followed mostly in developing country like India, as these offer fast turn-over \& are more profitable. This is normally a cosmetic strategy, restricted to the facade and offers a sense of safety due to the impressive new looks. The really needed repairs i.e. Structural repairs to the actual load-bearing structural members are often missed. Rather structural distress is camouflaged and buried beneath finishes. Thereby damage syndrome recurs and continues unabated. The ordinary classical methods of repair/rehabilitation 
like re-plastering, re-concreting, jacketing and shot creting etc. are often seen not to offer satisfactory results. It is often found that in traditional repairs, the same problem may recur fast. Investigations have brought out that the repair measures in such cases failed basically due to two reasons for RCC buildingsi.e.Corrosion of steel not being totally removed and Bonding between old and new concrete being inadequate.

For repair of any concrete structures, use of construction chemical is very common in advanced countries, for obtaining long term results, which in India is still very much lacking. It is difficult to match the response of the non-repaired and the repaired areas in rehabilitated structures. In India we are yet to opt for new technologies and materials on large scale to resolve the difficulty of attaining durable repaired structures on long term basis. In fact normal periodical maintenance is often very much lacking $\&$ thereby requirement of rehabilitation is also increasing.

There is a growing National/International concern about the premature deterioration of our buildings/structures, particularly concrete structures. Cement concrete is one of the most widely used construction material and has proved to be almost indispensable to the present day civilization. Though concrete is quite strong mechanically, it is highly susceptible to deterioration and thus gets damaged \& even fail ultimately, unless some measures are adopted to counter deterioration. Such measures would enhance the durability of structures. The maintenance of building is a lifelong continuous process. It has been observed that the minimum maintenance of concrete structures require an integral approach which need the introduction of as much preventive measures as possible in accordance with the basic established concept -"Prevention is always better than cure". Repair/rehabilitation/retrofitting is the fastest growing segment of the concrete industry. Across the globe, billions of dollars are spent annually in repair and restoration of distressed concrete structures. Thus selection and evaluation of repair materials and protective coatings is receiving more and more attention among Civil Engineers in the recent past. The new technologies and new repair materials, which have been extensively being used by the advanced countries, are also being tried in developed country like India. This paper highlights the present state of maintenance especially in developing country like India and about the utilization of those new techniques/materials for repair/restoration of the buildings/structures, for long term sustainable development.

\section{Major Causes For Deterioration Of Structures}

Concrete normally provides excellent corrosion protection to embedded reinforcement. The high alkaline environment in concrete results in the formation of a protective oxide film on steel bars. However unless concrete is well compacted and dense, it is susceptible to carbonation, losses its capacity to protect reinforcement. Some of the major causes for deterioration of concrete structures are brought out below:-

The deterioration of typical concrete structure starts from the time it is exposed to the elements of nature, primarily under high humidity, high temperature conditions \& variation in temperatures; thus certain parts of structures including roofs and structural elements directly exposed to weather condition, are more susceptible to deterioration. The deterioration of materials such as concrete \& reinforcement reduce the strength of the structural members. While elements such as temperature variations, pollution, wind, rains, floods etc. contribute towards deterioration; sometimes changes in environment after construction and changes in functional requirement also contribute towards premature deterioration.

Corrosion of embedded steel is the prime cause of damages to the reinforced concrete structures. It is like a "CANCER", which progresses with slow deteriorating process and if neglected or not attended in time, may spread over a large area and cause extensive disintegration/deterioration of 
structural elements. It may even lead to catastrophic structural failure, in the absence of timely remedial measures. Various causes which create conducive conditions to accelerate/propagate rate of corrosion are as under:-

- Inadequate cover to reinforcement.

- Use of inadequate grade of concrete for the purpose.

- Use of rusted steel.

- Workmanship/workability/compaction, thus leaving concrete porous.

- Poor Unsuitable ingredients (both coarse \& fine aggregate).

- Use of high $\mathrm{W} / \mathrm{C}$ ratio resulting in fine hairline cracks in concrete during drying.

- Use of water containing high incidence of salts/sulphates.

- Wave action (alternate wetting and drying processes).

- Presence of harmful gases in the air.

- Contact with acids/fumes.

- Exposures to relatively high humidity $(>70 \%)$.

Apart from these, other main reasons for deterioration of any structure are:-

+ Foundation settlements.

+ Lateral movements.

+ Accidental overload.

+ Poor maintenance during service life.

\section{Method Of RePair, Rehabilitation \& Retrofitting}

The techniques and materials used for repair/rehabilitation/retrofitting and maintenance depend upon the extent of deterioration. Construction chemicals/Polymers entered the world of concrete during the late Sixties. Today one can say that they are an integral part of many concretes. Broadly, polymers are chemical compounds, which essentially consist of repeating structural units. Though polymers are in use in concrete for quite some time; they are known by the respective roles they play such as admixtures, bonding agents, sealants and so on. Some of the most commonly used polymer-modifiers in concrete \& mortar are ethylene vinyl acetate copolymer, styrene-butadiene co-polymer and acrylic resins. Polymer-concrete composites display several improvements in the mechanical properties, including substantial increase in the strength $\&$ modulus of elasticity. In India, though the use of polymers in the construction industry particularly in repair/rehabilitation \& maintenance [12,13] field is growing, we are yet to have our own set of standards \& Codes, which can ably guide both the specifier \& the customer in their proper use. There is large number of products available in the market. As such there is a requirement of coming up with general guidelines and standard evaluation techniques, which should enable users to make the best use of products available. We all will gain from such a standardisation.

\section{REQUiREMENT \& Method For RetrofitTing OF STRUCtURES}

Retrofitting/strengthening is a technical option for improving the strength and other attributes of resistance of building to seismic and other forces. The requirement of retrofitting of any structure is arises mainly due to the fact that old buildings which were designed as per old Codal provisions $[5,6,7]$ may not be having adequate strength as per requirement of latest Codal provisions. Moreover, in certain cases deterioration of concrete of foundation and other structural elements etc. takes place due to various reasons including settlement of soil strata etc. Foundations are a very important part of building. The strengthening is also required, whenever we want to increase any additional floor of a building due to increase in FAR etc. Shoring and underpinning are important in repair/retrofitting of any foundations. Shoring is the forms of 
temporary support given above the foundation to the existing building to avoid any damage due to collapse of the building during repair/retrofitting. Underpinning is the process of strengthening the foundation of an existing building by repair. The process of strengthening the foundation of an existing building is called underpinning. The main objective of underpinning is to transfer the foundation load to a lower stronger depth. The reason for underpinning can be due to any one of the followings:

+ Larger than permissible settlement of the building

+ Increase in loading

+ Lowering the level of adjacent ground below the foundation of the building for some construction on the adjacent site.

There are various methods available for underpinning; one is Traditional Methods, others are Needle and pile underpinning of walls, Angle piling and Underpinning of Column Foundations by Jack Pile Method. Further, there are methods available for improving Foundations on Expansive Clays also. The Strengthening of RC Beams, Columns and Slabs can be carried out by Plate Bonding, RC Jacketing and by FRP systems. The Strengthening of Columns and Beams can be done also by RC Jacketing [11]. RC jacketing is jacketing with additional layer of steel and concrete $[14,15]$. It is one of the simple methods of strengthening of columns and beams. The RC slab Strengthening is carried out by Concrete Overlay. This is applied, where RC slab already constructed but found having structural deficiencies. In India, due to changes in codal provisions particularly for earthquake code, most of the existing old important buildings require retrofitting for structural safety against calamity like earthquake, tsunami and cyclone etc.

\section{REPAIR, REHABILITATION \&RETROFITTING MATERIALS \& TECHNIQUES}

\section{Polymer}

High strength, resilient materials which have high resistance to attack from chlorides \& sulphates are normally used for repair materials. The polymer modified concrete (PMC)/polymer modified mortar, which are commonly used as repair material has following properties:-

- High compressive strength at early age.

- Increased flexural \& tensile strength.

- Water tightness

- Adhesion

- Resilience, durability \&impermeability etc.

The polymer to be used is latex. SBR latex or other equivalent polymer should be used. It imparts the following properties to concrete.

- High strength

- Resilience

- Impermeability

- Resistance to carbonation \& chloride ion penetration.

The polymer is mixed in water prior to addition in cement concrete. The $\mathrm{PH}$ value of polymer should be more than 7.5 . The 28 days flexural strength should be at least $50 \mathrm{~kg} / \mathrm{cm}^{2}$. The minimum compressive strength is $150 \mathrm{~kg} / \mathrm{cm}^{2}$ at 3 days $\& 350 \mathrm{~kg} / \mathrm{cm}^{2}$ at 28 days. The split tensile strength should be at least $25 \mathrm{~kg} / \mathrm{cm}^{2}$ at 28 days. 


\section{Classification of Admixtures}

The admixtures can be classified according to type of material constituting the admixtures or to the characteristic effects of their use. The Table 1 shows how admixtures used for repair/rehabilitation is classified $[3,4]$.

\section{Epoxy Mortar/Grouting}

Epoxy mortars are used for repair of spalled concrete in underside of slab floor/roof slab \&chajjas having damage less than $75 \mathrm{~mm}$. Epoxy grouting is used normally for filling of cracks. Epoxy grouting systems have high mechanical strength. They obtain strength only in a few hours and are resilient in nature. Epoxy systems are immune to sulphate $\&$ chloride attack and are impermeable. They have got high compressive \& tensile strength also. Since epoxy grouting system can be injected into even hair line cracks, effective repairs can be carried out with them.

\section{Polymer Coating}

For enhancing the life of structure, coatings like IPN (Interpenetrating Network) or other equivalent polymer should be applied on all the concrete surface of the structure. The coating prevents any future ingress of air $\&$ harmful chlorides, sulphates etc. into the structure. It thus protects the entire structure from corrosion \& spalling. However, these coats are to be applied periodically, normally with interval of 5 years or so, depending on type of product being used.

\section{METHODOlOgy For RePAIR, REHABILITATION\& RETROFITTING}

\section{Common Guide Lines}

Presently number of companies is manufacturing various construction chemicals for repair/rehabilitation of civil engineering structures, in India. Various products manufactured by these companies cover all the repair materials available in India. However, their product range \& utility varies. In case corrosion of steel has not started but carbonation of concrete has taken place unto reinforcement surface, coating of required thickness can be applied to prevent/retard the carbonation process. Depending upon the severity of carbonation, polymer or epoxy resins or polymer modified mortar concrete provide adequate protection. Such coating also stops penetration of chloride and other deleterious elements.

Whenever the process of corrosion has set in, the restoration techniques depend on the extent of damage to the concrete and or steel. But following guidelines are common:-

- Remove all unsound concrete \& expose reinforcing steel all round.

- De-rust the steel by appropriate methods viz sand blasting, brushing \& applying rust removers etc.

- Restore reinforcement with anchorages i.e. shear connectors, wherever required.

- Apply tack/binding coat of polymers or Epoxy based materials.

- Use one of the several stitching techniques to restore concrete to the original surface level.

- Injection of cement slurry or polymer modified slurry or epoxy of suitable grade to fill up the pores, internal cracks or segregation.

- Apply suitable protective coating.

\section{Case Studies}

\section{Case Study-1: Repair/Rehabilitation of Jetty at Mumbai, India}

The author has successfully used various admixtures for major rehabilitation of wharves along with other repair works of caissons, dry dock etc. costing Rs.50 million (App.) at Bombay 
(Mumbai), India. The two wharves (Contiguous to each other) having width of $16.45 \mathrm{~m}$ and total length of $500 \mathrm{~m}$, was constructed during 1957 and 1967 (one having length of $350 \mathrm{~m}$ and other of $150 \mathrm{~m}$ ). The damages observed were excessive spalling of concrete, formation of wide cracks, excessive corrosion, falling of fenders and shearing off of piles etc. In general, it was observed that various structural elements after these have been exposed/chipped off showed much more deterioration than was observed at the time of the site survey.

The two wharves were composed of fender portals, bollard portals, curtain wall (on one side of wharf only), wailings (connecting piles at the bottom of the bracing level), Deck slab $(37.5 \mathrm{~cm}$ thick) and wearing coat $(17.5 \mathrm{~cm}$ thick) over deck slab. Apart from a visual and dimensional survey, various other tests were carried out to diagnose distresses. Cover meter test, half-cell potential survey, ultrasonic pulse velocity test, petrography test, core test, water permeability test, chloride sulphate test and porosity test were carried out. In addition, analytical assessment of residual strength was also made. The structure being very old, design calculation/details were not available. Using a computer, a structural analysis was carried out that showed that all structural members were adequately designed based on earlier codal provisions. Because of the extent of deterioration repairs were required to wharf portals frames, curtain wall, wailings, deck slab, wearing coat and fenders. The repair methodology adopted for different types of defects are as follows:-

+All cracks at various locations were filled with epoxy grouting under pressure. The stages involved in grouting are:-

- Cutting ' $\mathrm{V}$ ' grooves with pneumatic cutter.

- Drilling of holes, at intervals.

- Fixing of entry ports.

- Application of epoxy sealant.

- Cleaning of grooves with compressed air.

- Injection of Epoxy under pressure

- Cutting of entry ports.

- Grinding of sealant.

+ Spalling of concrete was repaired by various methods depending on locations. For soffit of slabs \& fenders where the depth of deterioration was less than $75 \mathrm{~mm}$, epoxy mortars were used. The sequences of activities involved were as follows:-

- Square cutting the boundary of damaged concrete.

- Chipping the spalled surface by pneumatic chipper.

- Removing rust from existing reinforcement by wire brushing.

- Welding of additional reinforcement after carrying out anti-corrosive treatment and an epoxy coating.

- Removing dust from surface of concrete and reinforcement by compressed air, drying of the surface before applying coating of epoxy.

- Applying an epoxy coat within an interval of 15 to 30 mins after mixing of resin \& hardener and quartz sand, in the proportion of $100,50 \& 800$ by weight. Air curing, for $48 \mathrm{hrs}$.

For piles, beams, wailings, bracings and fenders/soffit of slabs (having a depth of deterioration greater than $75 \mathrm{~mm}$ ), polymer modified concrete (PMC) were used. The stages involved in application of polymer modified concrete (PMC) is similar to that of epoxy mortar, except for mix of PMC and curing requirement. In PMC the materials used were cement, quartz sand, polymer \& water in the proportion of 100, 400, 15 and 30 by weight, for the damaged portion of structural member having shallow depth up to $75 \mathrm{~mm}$. However, where damaged portion is considerable and having thickness more than $75 \mathrm{~mm}$, cement, quartz sand, polymer water \& 
aggregate ( $20 \mathrm{~mm} \&$ down grade) was used, in the proportion of $100,200,15,35 \& 400$ by weight. Further, in case of PMC, water curing is also required. One pile which was sheared off (because of which the jetty was declared non-operational) was replaced by two piles after cutting the deck slab, lifting the slab by jacks and casting two new piles under water by bored cast-in-situ method and thereby restoring the structure to its original position. In other locations only a wearing coat, bonding coat of epoxy resin needed to be applied to the concrete. For repairs to the curtain wall (which is not a very important element of the structure) gunitting was used. Forenhancing the life of structure, a special penetrating thermosetting polymer was applied over the entire concrete structure including fender, after cleaning the structure by sand blasting.

The repair/rehabilitation work of the two wharves costing approximately Rs.30 million carried out during 93-94, appears to have stopped the deterioration and no further deterioration has been observed by visual inspection.-[16], after about more than 20 years since the repair/rehabilitation work was carried out. It is expected that this work will extend the service life of the facility for another 15 to 20 years, with normal periodical maintenance.

The Author has planned and got executed repair/rehabilitation/retrofitting of various types of structures like residential accommodation at, commercial accommodation, swimming pools and water tanks etc. by similar procedure and found the procedure is very effective.

\section{Case Study-2: Rehabilitation of RCC Overhead Reservoir at Siliguri, WB, India}

A study was carried out in March-April 96 for an overhead tank of 50,000 gallons capacity resting on staging of $16 \mathrm{RCC}$ columns braced together at different levels. The tank is located in North Bengal. The tank was constructed in the year 77-78. The tank having dimension of $9.3 \mathrm{x}$ $9.3 \times 3.4 \mathrm{~m}$ is resting on columns of size $300 \times 300 \mathrm{~mm}$. The columns are interconnected at 3 different levels through bracings of size $250 \times 250 \mathrm{~mm}$; Record drgs/CA drgs were not available. The distress in staging was noticed in the beginning of 1994. The distress was manifested in the form of cracks, spalling of concrete, rusting of steel in the bracings \& columns. The cover to reinforcement of column \& bracing was grossly inadequate.

In most of the cases, the spalling of concrete occurred from the bottom of bracings. Horizontal cracks were also observed at several places of a number of bracings. Exposed reinforcements are badly rusted. At the Zone of lapping of reinforcement, the quantum of reinforcement is very high $\&$ there is inadequate bonding between concrete $\&$ reinforcement at that zone. Similarly spalling of concrete has occurred from the corner of column along with vertical cracks.

There was no sign of tilting or settlement of foundations. However, some seepage from the bottom of tank was observed. The water container was otherwise found in sound condition, as there was no visible sign of distress on external or internal surface except top slab cover of tank (from inside), which is having exposed rusted steel. The process of rusting of reinforcement and deterioration of concrete is observed to be progressing at a rapid speed, by comparing with the distresses noticed first time in the beginning of 1994, due to severe weather condition in that area. Any further delay in repair might cause sudden collapse of the structure due to the external forces like heavy wind \& earthquake etc.

\section{DISCUSSION}

The tank was having major problem with bracings. The concrete of almost all the bracings have deteriorated extensively. As brought out, the spalling of concrete has occurred mainly from the bottom of the bracings, due to inadequate cover. The rusting/spalling started at the initial stage from the zone of lapping of reinforcement, (where quantum of reinforcement is very high), which subsequently progressed in Zones where there was no lapping of reinforcement. Thereby, horizontal cracks have developed, even in those zones causing spalling of concrete from there. 
Similarly, due to insufficient cover to the reinforcements of columns, there was development of small vertical cracks at the initial stage. Subsequent rusting of reinforcement has caused spalling of concrete \& development of vertical cracks in columns along the reinforcement.

Adequate precaution in terms of additional supports, careful dismantling of old concrete with modern equipment is an essential requirement in this case, to avoid any permanent damage to main structure. The major rehabilitation of this nature can be avoided, if system of proper periodical inspection and regular maintenance can be implemented on ground. Any seepage in water tank particularly through shaft type staging's needs special attention, as this might result into sudden collapse. Here in this particular case also the deterioration would have been much faster, if there had been added seepage through main structure. Here effect is mainly restricted to adverse humid atmosphere on RCC supporting structure having inadequate reinforcement cover.

\section{REMEDIAL MEASURES}

The following remedial/rehabilitation measures were suggested:

- All unsound concrete to be removed by electric cutter/pneumatic chipper and reinforcement to be exposed all round.

- Existing steel to be de-rusted properly by brushing and applying rust removers etc.

- Wherever existing reinforcement is reduced by $20 \%$ or more, additional reinforcement duly cleaned to be provided and welded on both sides.

- Epoxy based bonding material to be applied on old concrete surface (including old steel surface), after removing rust from the surface of concrete. The surface to be dried properly before applying bond epoxy coat, as per manufactures instruction.

- Polymer modified concrete mortar to be applied. The materials to be used for mortar are cement, Quartz sand, polymer \& water in the proportion of $100,400,15 \& 30$ parts by weight. For damaged portion of member having depth more than $75 \mathrm{~mm}$ cement, quartz sand, aggregate ( $20 \mathrm{~mm}$ and down grade), polymer \& water in the proportion of 100, 200, $400,15 \& 35$ parts by weight to be used.

- $20 \mathrm{~mm}$ thick plaster in cement mortar 1:4 to be applied to overcome the deficiency of reinforcement cover.

The subsequence of repair is very important in this whole repair scheme, because of critical condition of staging. The repair of all the bracings in appropriate groups initially was suggested, and then the columns to be repaired in a group of maximum four at a time, after transferring load through strong steel prop to the bracings (below)/ground. Further it was recommended that minimum three years performance guarantee clause be included in the tender for repair works. Though numbers of companies were manufacturing construction materials/chemicals, the products of following companies or equivalent were suggested for use:

- Hindustan Ciba-Geigy Ltd., Bombay

- Sika Qualcrete Pvt. Ltd., Calcutta

- Krishna Conchem Products Pvt. Ltd., Bombay

- Fosroc Chemicals (India) Ltd., Bangalore

- MC-Bouchamie (India) Pvt. Ltd, Bombay

Based on this report prepared by the Author of the Paper, the work was carried out successfully in the year 1998 and is fully functional now also. 
Civil Engineering and Urban Planning: An International Journal (CiVEJ) Vol.3, No.2, June 2016

\section{Case Study-3:A Double Storied Load Bearing Residential Building at Mumbai, India \\ Salient Features}

- Year of Construction $\quad$ :1965

- Investigation done : 1998

- Type of Structures : Double-storied Load bearing structures

- Type of Foundations : : Spread Footing

- Number of Quarters : : 44

\section{Visual Observations}

- Extensive cracking and spalling of concrete in sunshades, Chajja, Staircase and beams etc.

- At some places reinforcement was exposed and corroded heavily.

- Major cracking observed on plastering on all faces.

- Severe seepage seen in most of the roof slab and external walls.

- Waist-slab of Staircase and soffit of beams exhibited delamination over 50\%.

\section{In-Situ Evaluation andNon-Destructive Tests}

\section{Delam Survey}

Every column and beam was tapped by three different types of hammers. Most effective was the medium hammer, which gave, delams for 15 to $25 \mathrm{~mm}$ depth. The hollow sound was recorded as hollow and the results of each structural member recorded on to observation sheet and that area evaluated for remedial measures.

\section{Rebound Hammer Test}

The rebound numbers measured on concrete surfaces

\section{Ultrasonic Palse Velocity Test}

Values of the pulse velocity varied in the range of from $3.0 \mathrm{~km} / \mathrm{sec}$ to $4.8 \mathrm{~km} / \mathrm{sec}$.

\section{Half-Cell Potential Test}

Electrical Potential Values indicate that severe corrosion had taken place in some areas, as observed during the visual survey.

\section{Carbonation Test}

Carbonation has taken place beyond the reinforcement levels

\section{Conclusion}

- The main cause for distress to RCC element-

- Inadequate thickness of cover concrete

- Highly permeable and porous concrete

- Carbonation of concrete

- Most distressed portions were chajjas along with lintel/beam, which is directly exposed to marine atmosphere and frequented by alternate wetting and drying.

- Seepage observed in roof slab was due to leakage from pipe line. 


\section{Recommended Repair Methods}

- All sunshades/Chajjas including balcony wall, side wall of steps and slab (partly) to be dismantled.

- In the joints between old and new concrete, epoxy based bonding materials to be applied on old concrete surfaces.

- Before removing affected RCC potion, temporary support to be provided properly.

- The use of light weight pre-cast lintels/chajjas in liewof cast-in-situ was suggested. Accordingly corrugated sheets were provided.

- For RCC members, where overall integrity found good, cracks to be filled by putting epoxy grouting under pressure. For spalled concrete, polymer mortar/concrete with epoxy bond coat to be provided.

- The painting to complete surface to be applied with cement based paint with addition of polymeric compound.

The complete repair work was got completed in $2000 \&$ the performance after about 16 years is very satisfactory. The Author was directly involved in complete assessment and planning of repair scheme and giving guidance during execution etc.

The staging of water retaining structure, are always exposed to the action of moisture/rain \& as such there is a very strong need to provide well compacted dense concrete with adequate cover to avoid rusting of reinforcement and weathering action on concrete members/staging.

The overhead tanks need to be periodically inspected by the maintenance staff of GE and its soundness should be reported on 6 monthly basis through a regular report. This will function as an early warning system and avert the type of deterioration, observed in the tanks. Normal/special repairs of all the affected tanks need to be undertaken in a group, The present system of carrying out only periodical services of giving one coat of snowcem/colour wash every year, over the concrete surface even with cracks, spalling of concrete etc. needs to be dispensed with. No periodical services should be done, unless structural soundness/stability is established. Presently numbers of companies are manufacturing various polymer based construction chemicals, which can be utilized effectively for repair/rehabilitation of this type of structure, as soon as any deterioration is observed in the structure.

The Author was involved in planning and formulating this rehabilitation scheme. The work was subsequently executed under guidance of the Author successfully and serving the purpose now also.

\section{Precautions In The Use Of Chemicals In Execution Of Work}

Presently in India we are not having any detailed codal provision for utilisation of various construction chemicals/polymers \& utilisation is restricted to a select few privileged ones who are acquainted with the same. In the absence of proper detailed codal provision, a careful attention should be given to the instruction given by the manufacturer of the polymers. A polymer should be employed only after appropriate evaluation of its effects, preferably by use with the particulars materials \& the condition of use intended. Such an evaluation is particularly important in our country, as the chemicals/polymers have mainly been developed in country having colder climate. They therefore require long term testing under tropical climate. Besides, such evaluation is also needed under the following situations:-

- Special types of cement are specified.

- More than one polymer to be used, together.

- Mixing \& placing is done at temperatures well above or belowthegenerally recommended concreting temperatures. 
The repair work needs to be executed in accordance with project documents. The repair process, especially concrete removal and reinforcing repair, may alter the load distribution of the structure and the members being repaired. Proper shoring and bracing needs to be provided throughout of the construction. Quality control throughout the repair process is essential to any successful project. Appropriate inspection by the Engineers and periodical testing at site \& in laboratory is to be performed and ensured on regular basis, for long lasting solution.

\section{CONCLUSION}

The repair/rehabilitation/Retrofitting of Concrete repair projects are very challenging, as is true with most repair and renovation projects. Repair/Rehabilitation of concrete structure is comparatively a new subject in India. It is a real challenging task to carry out the repair/rehabilitation work, when structure has already undergone major structural damages/deterioration. As such, there is a requirement of periodical/timely assessment and maintenance with latest available techniques and materials as described in this paper. This will go a long way to arrest deterioration and extend the lease of life to the structure. As the time passes, many more concrete structures will come up for major rehabilitation. Time has come to have a structural auditing of all the old concrete buildings/structures, which were constructed during sixties and earlier. Depending on the severity of the environmental effect, the restorative measures can be selected. In poor country like India, we cannot afford to spend money on replacing the building, which is against implementation of green building concept also. As such selection \& evaluation of right repair material and protective coatings will save enormous money \& time by reducing the frequent repair costs of already repaired concrete buildings/structures.

To modify/improve the properties of concrete or mortar, a large number of polymers/admixtures have been tried and extensively used in other countries. World over polymers/admixtures have been in use for over 45-50 years and their long term behaviour patterns are known. The superiority of polymer modified mortars/concretes over normal mortars/concretes in repair/rehabilitation field is established beyond doubt. In India, such effective polymers/admixtures have only become available during last two decade mainly. Now a number of internationally known and time tested polymers/admixtures are available all over India. However, before using various new polymers/construction chemicals available in the market, one must be familiar with the products and its limitations. Further, the repair/rehabilitation works should be undertaken only after ascertaining properly the cause of deterioration. It is imperative that the Engineer understands the reasons which led to damage and or deterioration prior to developing a repair programme. The underlying causes should be corrected, although it is a difficult process. The polymers/admixtures should form a permanent part of original construction and repair/rehabilitation/retrofitting \& maintenance of concrete structures in coming years, for long term sustainable development.

\section{ACKNOWLEDGEMENTS}

The authors would like to thank everyone, just everyone!

\section{REFERENCES}

[1] Bhattacharjee J ( 2015) : "Need for repair/retrofitting of Concrete Structures using latest materials \& Techniques", in International Conference of NCB, in New Delhi on 01-04 Dec15,(PP 710-713)

[2] Paul. H Jay, ( 2002 ) : "Repair, Renovation \& Strengthening of concrete structures" in Seminar on "Evaluation \& Rehabilitation of concrete structures", in Mexico city on 11-13 Sept, 2002, PP 1- 11.

[3] Bhattacharjee, J.(1997): "Utilisation of Super plasticizers\& other Chemical admixtures in Rehabilitation of Marine Structures along with a Case Study", in Proceedings of International Conference organised by CANMET/ACI at Rome, Italy on 7-10 Oct.1997. PP 23-26. 
Civil Engineering and Urban Planning: An International Journal (CiVEJ) Vol.3, No.2, June 2016

[4] Seminar Proceedings on "Admixtures for Concrete" (1996), Concrete for the 21st century Meeting the challenges”, ACI (Maharashtra India chapter), at Bombay on 02 May 96, PP 95-126.

[5] IS 2911,"Indian Standard Code of Practice for Design and Construction of Pile Foundations", Parts 1 to 4, Bureau of Indian Standards.

[6] IS 13920:1993, "Indian Standard Code of Practice for Ductile Detailing of Reinforced Concrete Structures Subjected to Seismic Forces," Bureau of Indian Standards.

[7] IS 13935:1993, "Indian Standard for Repair and Seismic Strengthening of Buildings Guidelines", Bureau of Indian Standards.

[8] Alcocer, S.M. and Jirsa, J.O. (1993), "Strength of Reinforced Concrete Frame Connections Rehabilitated by Jacketing”, ACI Structural Journal, American Concrete Institute, May-June Vol. 90, No. 3, pp. 249-261.

[9] K.B.Rajoria, Ashok Basa, (2010) The Institute of Engineers(I), "Rehabilitation and Retrofitting of Structures" published by Macmillan Publishers India Pvt.Ltd.

[10] Hand Book on "Seismic Retrofit of Buildings" (2008) by CPWD, IBC\& IIT, Madras, by Narosa Publishing Pvt.Ltd,

[11] Hand Book on "Repairs and Rehabilitation of RCC Buildings" (2011) (published by CPWD, Govt. of India, New Delhi.

[12] R.C.Misra, K. Pathak (2009) Book on "Maintenance Engineering and Management" published by PHI Learning Pvt. Ltd.

[13] P.C.Varghese (2014) Book on "Maintenance, Repair \& Rehabilitation \& Minor Works of Buildings" published by PHI Learning Pvt. Ltd.

[14] Dr.B.Vidivelli, (2014) book on "Rehabilitation of Concrete Structures" by Standard Publishers Distributors.

[15] R.Dodge. Wodson, (2009) book on "Concrete Structures, Protection, Repair and Maintenance", published in Burlington, USA.

[16] Bhattacharjee J ( 2016) : "Rehabilitation/Retrofitting of Concrete Structures along with Case Studies", in 2 nd International Conference of of CEU-16, Dubai, UAE on 23-24 Apr16. 
Civil Engineering and Urban Planning: An International Journal (CiVEJ) Vol.3, No.2, June 2016

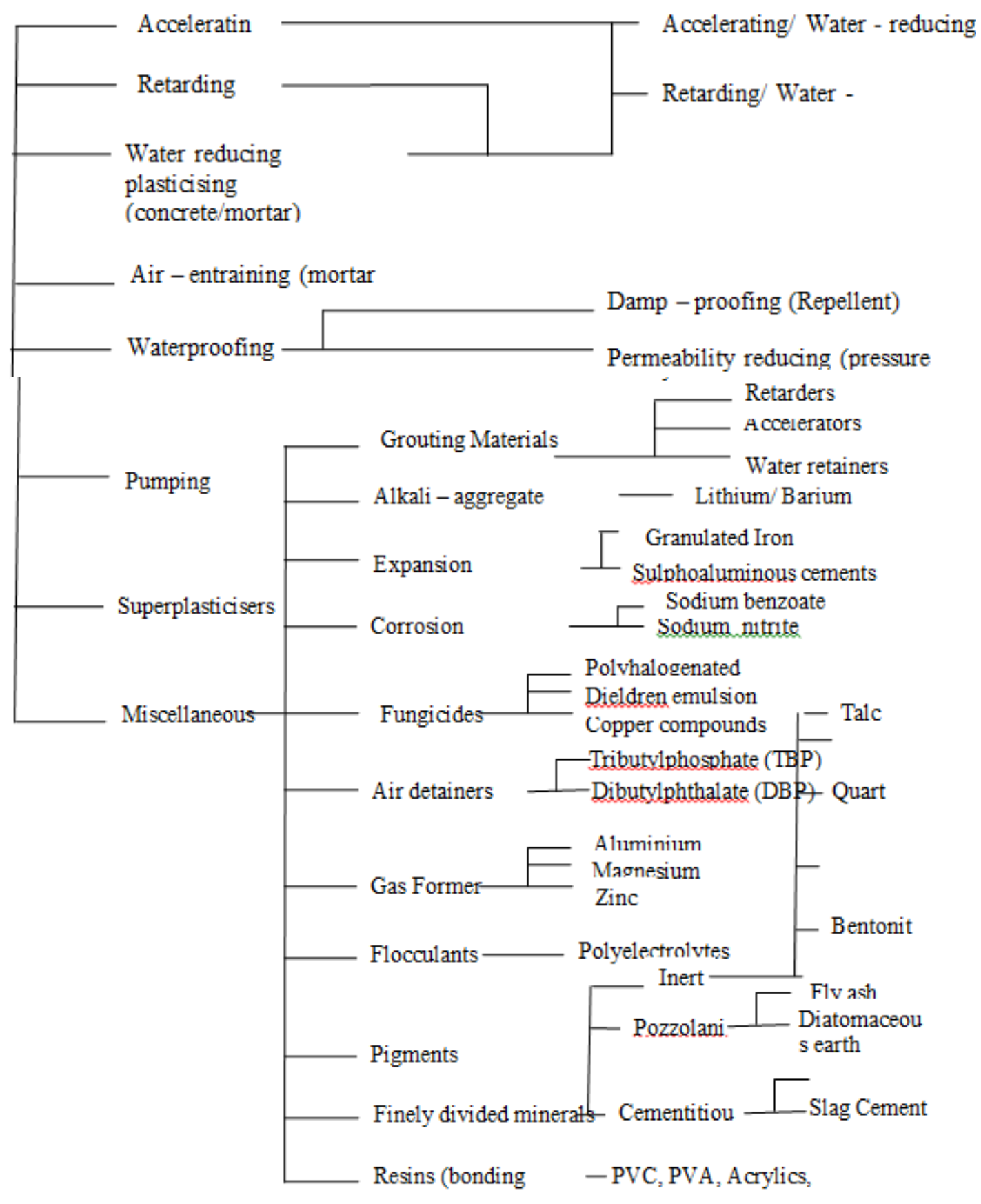

Table - 1 - Classification of Admixtures 


\section{Author}

Er. J.Bhattacharjee is a Professor \& Advisor in Civil Engineering Deptt. of Amity University, Noida since Jan 2012. He is a former Chief Engineer \&Jt.Director General (Ministry of Defence/MES). He obtained his B. E (Civil) degree from B.E. College, Sibpore, Calcutta; M.Tech. (Structural) from IIT Madras \& had M.Phil degree from Madras University. Presently pursuing PHD on Disaster Management. He has done number of Courses including prestigious NDC (National Defence College) Courses, Senior Defence Management Course at CDM, Secunderabad, while serving in the

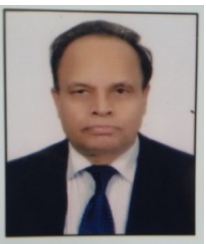
Deptt. He has a vast experience of over 45 years in the industry in planning, Designing \& execution of various types of Civil Engineering works including about 5 years in Multinational Consultancy organization "Gherzi Eastern Ltd" as a Head of Engineering at Delhi. He has Presented/published technical papers 77 No's so far on various subjects in National /International Seminars/Conferences and Journals. $\mathrm{He}$ is a Life Member of 14(fourteen) Technical Bodies in India/abroad\& is a Governing Council member of Indian Building Congress (IBC).He has received two prestigious "Awards for Excellence" from Indian Building Congress (IBC) for two prestigious Projects of Consultancy jobs. Received "CIDC Vishwakarma awards" for Best professionally managed company for two years in $2009 \& 2010$ on behalf of the company. He was considered as a Rehabilitation expert in the Deptt. He has developed and teaching number of new courses at under graduate \& Post graduate level, while serving in the Deptt. of Civil Engineering at Amity University 